\title{
ANALISIS PERBANDINGAN PENGENDALIAN PERSEDIAAN BAHAN BAKU METHANOL ANTARA PENDEKATAN MODEL ECONOMIC ORDER QUANTITY DENGAN JUST IN TIME PADA CV MAMABROS SERVICINDO BATAM
}

\author{
Melpa Syari Kristiani Turnip ${ }^{1}$ \\ Dwi Kartikasari, S.T, M.B.A ${ }^{2}$ \\ Prodi Administrasi Bisnis Terapan \\ Politeknik Negeri Batam \\ Tel/HP : 081266314730 \\ Email: melva.syari@yahoo.com
}

\begin{abstract}
Abstrak
Penelitian ini bertujuan untuk mengetahui metode pengendalian persediaan yang optimal digunakan oleh CV Mamabros Servicindo Batam dengan membandingkan antara kebijakan yang telah dijalankan perusahaan dengan dua metode persediaan yaitu Economic Order Quantity dan Just In Time. Teknik pengumpulan data yang digunakan dalam penelitian ini observasi, dokumentasi dan wawancara. Metode analisis data yang digunakan dalam penelitian ini adalah EOQ formula, Safety Stock, Reorder Point serta Just In Time Formula. Hasil penelitian menunjukkan bahwa sistem EOQ dan JIT lebih efisien dibandingkan dengan sistem persediaan perusahaan. Namun sistem JIT memiliki tingkat efisiensi biaya yang lebih tinggi dibanding sistem EOQ. Pada tingkat permintaan persediaan methanol 41.273 liter, sistem persediaan perusahaan menghasilkan biaya persediaan sebesar Rp 6.946.052, dibandingkan dengan JIT yang hanya memiliki biaya persediaan sebesar Rp 3.056.263 dapat menghemat biaya sekitar Rp 3.889 .789 atau 55\% lebih efisien dari biaya persediaan perusahaan. Sedangkan metode EOQ menghasilkan biaya persediaan sebesar Rp 3.700.608, atau hanya 46\% lebih efisien dari biaya persediaan berdasarkan kebijakan perusahaan.
\end{abstract}

Kata kunci: Pengendalian persediaan, Economic Order Quantity, Just In Time, Biaya persediaan

\section{PENDAHULUAN}

Peranan persediaan pada perusahaan sangat penting untuk mendukung kegiatan operasional perusahaan, yaitu untuk mencapai tujuan operasional perusahaan dalam memperoleh laba yang maksimum, kontinuitas dan perkembangan usaha. Perencanaan persediaan berhubungan dengan jumlah persediaan optimal yang harus dimiliki perusahaan dan pengaruhnya terhadap biaya persediaan. Jumlah persediaan yang terlalu kecil, dapat mengganggu produksi perusahaan karena perusahaan tidak dapat beroperasi pada kapasitas penuh sehingga sumber daya perusahaan ada yang menganggur, kelebihan persediaan akan menambah biaya operasi seperti biaya penyimpanan, kerugian akibat penurunan harga pasar, dan kerusakan persediaan. Oleh karena itu perlu digunakan teknik perencanaan dan pengendalian agar tidak terjadi kekurangan maupun kelebihan persediaan bahan baku.

CV Mamabros Servicindo merupakan sebuah usaha berkembang yang didirikan sejak tahun 2014 oleh Khris Gajahera dan terletak di Ruko Grand California Blok A1 No.7 Batam Center. Perusahaan ini bergerak dibidang produksi kebutuhan laundry seperti parfum, deterjen serta pelembut dan pelicin pakaian. CV Mamabros Servicindo Batam 
selalu menjaga kualitas produk yang mereka pasarkan dengan menggunakan bahan baku yang berkualitas dan memastikan bahwa persediaan bahan baku senantiasa mencukupi demi menjaga kelancaran produksi. Sistem pengendalian persediaan yang digunakan oleh $\mathrm{CV}$ Mamabros Servicindo sangat sederhana, mereka melakukan pemesanan bahan baku secara rutin sebanyak 1 kali pemesanan dalam jangka waktu 1 (satu) bulan. Pemesanan tersebut dilakukan dengan perkiraan secara tradisional. Apabila jumlah ketersediaan bahan baku produksi sudah mulai berkurang, maka mereka akan mengajukan pemesanan kembali bahan baku kepada atasan yaitu manajer produksi, sehingga sering terjadi penumpukan bahan baku digudang dikarenakan kebutuhan bahan baku tidak sesuai dengan kebutuhan produksi. Hal ini tentunya akan mengakibatkan peningkatan biaya pengeluaran perusahaan seperti biaya pemesanan dan biaya penyimpanan bahan baku.

Secara umum, penelitian ini mempelajari tentang pengendalian persediaan bahan baku pada perusahaan, dan membandingkan antara satu sistem dengan sistem lainnya. Dalam tulisan ini akan dikemukakan dua sistem persediaan, yaitu Economic Order Quantity (EOQ) dan sistem Just in Time (JIT). Pengertian (Economic Order Quantity) adalah salah satu teknik kontrol persediaan yang meminimalkan biaya total dari pemesanan dan penyimpanan. Tujuan dari EOQ ini adalah meminumkan kombinasi dari ongkosongkos pesanan dan penyimpanan dari persediaan, sedangkan Menurut Garrison dan Noreen (2006) Just In Time (JIT) adalah : "sistem pengendalian persediaan dan produksi yang menghendaki bahan baku dibeli, dan unit yang diproduksi hanya sebatas kebutuhan dari pelanggan, sehingga biaya operasional dapat dieliminasi seminimal mungkin dan menuju persediaan mendekati nol (zero inventory), karena Just In Time (JIT) menganggap persediaan merupakan sumber pemborosan.

Penelitian ini diharapkan dapat menjadi pertimbangan bagi CV Mamabros Servicindo Batam untuk bahan evaluasi mengenai kebijakan dalam penentuan pengelolaan persediaan bahan baku yang telah digunakan selama ini dalam produksinya. Sedangkan manfaat secara teoritis diharapkan dapat menambah pengetahuan dalam bidang penelitian bagi penulis dan sebagai masukan dan referensi bagi penelitian berikutnya.

\section{KAJIAN PUSTAKA}

1. Persediaan bahan baku

Pengertian persediaan menurut beberapa ahli antara lain sebagai berikut: menurut Assauri (2008), persediaan adalah sebagai suatu aktiva yang meliputi barangbarang milik perusahaan dengan maksud untuk dijual dalam suatu periode usaha yang normal, atau persediaan barangbarang yang masih dalam pengerjaan/proses produksi, ataupun persediaan barang baku yang menunggu penggunaannya dalam suatu proses produksi.

Menurut Vincent Gaspersz (2012), klasifikasi fungsional persediaan antara lain:

\section{a. Fungsi decoupling}

Fungsi decoupling ini dipergunakan untuk item-item product supply, sedangkan untuk item-item produk akhir digunakan istilah safety stock. Decoupling stock menyimpan inventori untuk memenuhi "parent assembly", tujuan mengadakan decoupling stock untuk mencegah "idle time" dalam pabrik.

\section{b. Fungsi lot size stock}

Merupakan siklus pemesanan kembali untuk pengisian stock. Biasanya diterapkan pada finished good, work-in-process, raw material, dan MRO supplies.

c. Fungsi anticipation stock

Merupakan persediaan tambahan di atas basic pipeline stock untuk mencukupi proyeksi dari trend kenaikan penjualan, 
program promosi penjualan yang direncanakan, fluktuasi musiman, tidak beroperasinya pabrik, libur, dan lain-lain.

d. Stok pengaman (Safety Stock)

Stok pengaman digunakan untuk mencegah kemungikan kehabisan stok (stockout) akibat ketidakpastian permintaan atau supplies. Dalam hal ini diberikan tambahan persediaan untuk mengantisipasi permintaan melebihi ramalan atau pesanan pengisian kembali terlambat atau kuantitas yang dipesan lebih sedikit daripada yang dibutuhkan.

\section{e. Transportation Stock}

Merupakan item-item persediaan yang bergerak dari satu tahap ke tahap berikutnya, jadi transportation stock merupakan material transit diantara lokasi. Transportation stock paling lazim berkaitan dengan distribusi inventori.

f. Hedging Stock

Pertimbangan untuk mengadakan hedging stock didasarkan atas pertimbangan seperti kemungkinan terjadi pemogokan buruh dari industri pemasok bahan baku, prediksi kenaikan harga material yang tajam, ketidakstabilan pemerintah dari Negara-negara pemasok luar negeri, atau item-item yang memiliki waktu tunggu sangat panjang atau tidak tetap.

g. Service Parts

Merupakan item-item dalam inventori yang digunakan sebagai parts pengganti untuk pengoperasian peralatan atau keperluan lain. Service parts dipertimbangkan sebagai terpisah dari klasifikasi fungsional karena permintaan service parts sering sangat rendah dan berpola aneh, ongkos stockout sangat tinggi, pelanggan biasanya tidak hanya ingin tetapi senang membayar dengan harga yang jauh lebih besar daripada ongkos memproduksi item service parts tersebut.

\section{Metode Economic Order Quantity \\ Heizer dan Render (2010) menerangkan bahwa Economy Order}

Quantity (EOQ) merupakan sebuah teknik kontrol persediaan yang meminimalkan biaya total dari pemesanan dan penyimpanan. Metode Economy Order Quantity (EOQ) diutarakan Slamet (2007) dapat diartikan sebagai kuantitas bahan baku dan suku cadangnya yang dapat diperoleh melalui pembelian dengan mengeluarkan biaya minimal tetapi tidak berakibat pada kekurangan dan kelebihan bahan baku dan suku cadangnya. Menurut Riyanto (2011) Economic Order Quantity (EOQ) adalah jumlah kuantitas barang yang dapat diperoleh dengan biaya yang minimal atau sering dikatakan sebagai jumlah pembelian yang optimal.

Dari definisi-definisi diatas dapat disimpulkan Economic Order Quantity (EOQ) adalah jumlah pembelian persediaan yang dilakukan dengan efisien agar biaya persediaan keseluruhan menjadi sekecil mungkin. EOQ dihitung dengan memperhatikan variabel biaya persediaan. Ada 2 macam biaya yang digunakan sebagai dasar perhitungan EOQ, yaitu biaya pemesanan (ordering cost) dan biaya penyimpanan (carrying cost).

3. Metode Just In Time

Menurut Garrison dan Noreen (2006) Just In Time (JIT) adalah : "sistem pengendalian persediaan dan produksi yang menghendaki bahan baku dibeli, dan unit yang diproduksi hanya sebatas kebutuhan dari pelanggan. Definisi Just In Time menurut Simamora (2002) yaitu sistem manajemen pabrikasi dan persediaan komprehensif di mana bahan baku dan berbagai suku cadang dibeli dan diproduksi pada saat diproduksi dan pada saat (just in time) akan digunakan dalam setiap tahap proses produksi/pabrikasi. Implementasi sistem JIT pada pembelian menjadi sangat penting untuk menunjang keberhasilan penerapan JIT dalam system manufacturing secara keseluruhan. implementasi JIT pada pembelian akan sangat tergantung pada kesiapan dari pemasok untuk memasok bahan baku yang dibutuhkan setiap hari pada penyerahan 
tepat waktu. Pembelian JIT dapat mengurangi waktu dan biaya yang berhubungan dengan aktivitas pembelian seperti biaya pemesanan bahan baku tersebut maupun biaya penyimpanannya.

\section{METODE}

Penelitian ini dilakukan di CV Mamabros Servicindo Batam yang beralamat di beralamat di Ruko Grand California Blok A2 No 6-7 Batam. Waktu penelitian dilaksanakan pada bulan Februari 2017. Penelitian ini menggunakan metode penelitian deskriptif komparatif dengan pendekatan kuantitatif yaitu suatu metode penelitian yang bertujuan untuk membandingkan persamaan dan perbedaan dua atau lebih fakta-fakta dan sifat-sifat objek yang diteliti dengan cara mengumpulkan, mengolah, dan menganalisa berbagai berbagai macam data sehingga dapat ditarik suatu kesimpulan. Populasi dalam penelitian ini adalah persediaan bahan baku yang digunakan dalam proses produksi CV Mamabros Servicindo Batam selama satu periode. Untuk penetapan sampel penelitian dilakukan dengan pertimbangan bahan baku yang paling banyak digunakan untuk produksi. Bahan baku yang dijadikan sampel dalam penelitian ini diambil dari persediaan bahan baku methanol yang telah dilakukan sebelumnya oleh CV Mamabros Servicindo Batam pada tahun 2016.

Metode análisis data yang digunakan dalam penelitian ini adalah análisis Economic Order Quantity dan análisis Just in Time,

1. Análisis Economic Order Quantity Perhitungan EOQ dapat diformulasikan sebagai berikut (Heizer dan Render, 2010)
a. Menentukan
Economic
Order Quantity

$$
\operatorname{EOQ}=\sqrt{258}
$$

Keterangan:

$\mathrm{D}=$ kebutuhan bahan periode
$\mathrm{S}=$ biaya setiap kali pesan

$\mathrm{H}=$ biaya penyimpanan per unit per periode

$\mathrm{Q}=$ Kuantitas barang setiap kali pemesanan

a. Frekuensi pemesanan

$$
I=\frac{D}{E O Q}
$$

Keterangan :

$\mathrm{I}=$ frekuensi pemesanan dalam satu tahun

$\mathrm{D}=$ jumlah kebutuhan bahan selama setahun

EOQ = Kuantitas barang setiap kali pemesanan

c. Biaya Total Persediaan

$$
\text { Total Cost }=S x\left[\frac{D}{Q}\right]+H x\left[\frac{Q}{2}\right]
$$

Keterangan:

$\mathrm{TC}=$ Total biaya persediaan

$\mathrm{D}=$ jumlah kebutuhan barang dalam unit

$\mathrm{S}=$ biaya setiap kali pesan

$\mathrm{h}=$ biaya penyimpanan per unit per

periode

$\mathrm{Q}=$ kuantitas barang setiap kali pemesanan

d. Menentukan safety stock

$$
S D=\sqrt{\frac{\sum(x-\bar{x})^{2}}{n}}
$$

$\mathrm{SS}=\mathrm{SD} \times 1.88$

Keterangan :

$\mathrm{SD}=$ Standar deviasi

$\dot{x}=$ Rata-rata pemakaian

$\mathrm{x}=$ Pemakaian sesungguhnya

$\mathrm{N}=$ Jumlah data

$\mathrm{SS}=$ Persediaan pengaman (Safety

Stock)SD = Standar Deviasi

$\mathrm{Z}=$ Faktor keamanan ditentukan atas dasar kemampuan perusahaan (1.88) 


\section{e. Menentukan reorder point}

Reorder point $=(\mathrm{dL})+\mathrm{SS}$

Keterangan :

$\mathrm{ROP}=$ Reorder Point

$\mathrm{dL}=$ Tingkat kebutuhan per periode

$\mathrm{SS}=$ safety stock atau persediaan pengaman

\section{Análisis Just In Time}

Berikut analisis yang digunakan untuk menghitung jumlah pemesanan optimal dan total biaya persediaan menggunakan metode Just In Time (Hayundra, 2013)

a. Menentukan Jumlah Kuantitas Pemesanan Optimal

$$
Q n=\sqrt{n} Q
$$

Keterangan :

Qn = Kuantitas pemesanan optimal $\mathrm{n}=$ Jumlah optimal pengiriman selama satu periode

$\mathrm{Q}=$ Kuantitas pemesanan dalam unit

b. Menentukan frekuensi pemesanan bahan baku

$$
N=\frac{Q}{Q n}
$$

Keterangan :

$\mathrm{N}=$ Frekuensi pemesanan

$\mathrm{Q}^{*}=$ Jumlah kebutuhan bahan baku

Qn = Kuantitas pemesanan optimal
Tjit $=\frac{1}{\sqrt{\pi}}\left(T^{2}\right)$

Keterangan :

Tjit $=$ Total biaya persediaan JIT

$\mathrm{n}=$ Jumlah optimal pengiriman selama

satu periode

$\mathrm{T}^{*}=$ Total biaya persediaan

d. Menentukan Jumlah Pengiriman Optimal untuk Setiap Kali Pengiriman $q=\frac{Q n}{n}$

Keterangan :

$\mathrm{q}=$ Jumlah pengiriman yang optimal

dalam unit

Qn = Kuantitas pemesanan optimal

$\mathrm{n}=$ Jumlah optimal pengiriman selama satu periode

\section{HASIL DAN PEMBAHASAN}

Berikut ini adalah hasil penelitian dan pengujian yang telah dilakukan :

1. Pengendalian Persediaan Bahan Baku Aktual Perusahaan

Persediaan awal pada tahun 2016 sebesar 1.400 liter. Persediaan awal tersebut merupakan persediaan akhir pada akhir periode Desember 2015. Kuantitas pesanan dan tingkat persediaan rata-rata berdasarkan kondisi aktual pada tahun 2016 ditunjukkan pada tabel 4.4 di bawah ini:

\begin{tabular}{|c|c|c|c|c|c|c|}
\hline \multirow{2}{*}{ Bulan } & Persediaan Awal & Pembelian & Total Persediaan Awal & Pemakaian & Persediaan Akhir & Rata-Rata \\
\hline & \begin{tabular}{|l|} 
Liter \\
\end{tabular} & Liter & \begin{tabular}{|c|} 
Liter \\
\end{tabular} & Liter & $\begin{array}{c}\text { Liter } \\
\end{array}$ & Liter \\
\hline Januari & 1.400 & 4.000 & 5.400 & 2.799 & 2.601 & 4.001 \\
\hline Februari & 2.601 & 3.600 & 6.201 & 2.798 & 3.403 & 4.802 \\
\hline Maret & 3.403 & 3.000 & 6.403 & 3.260 & 3.143 & 4.773 \\
\hline April & 3.143 & 2.500 & 5.643 & 4.414 & 1.229 & 3.436 \\
\hline Mei & 1.229 & 4.600 & 5.829 & 3.100 & 2.729 & 4.279 \\
\hline Juni & 2.729 & 1.000 & 3.729 & 345 & 3.384 & 3.557 \\
\hline Juli & 3.384 & 2.000 & 5.384 & 4.186 & 1.198 & 3.291 \\
\hline Agustus & 1.198 & 4.000 & 5.198 & 3.462 & 1.736 & 3.467 \\
\hline September & 1.736 & 4.000 & 5.736 & 4.232 & 1.504 & 3.620 \\
\hline Oktober & 1.504 & 4.000 & 5.504 & 4.672 & 832 & 3.168 \\
\hline November & 832 & 5.000 & 5.832 & 3.426 & 2.406 & 4.119 \\
\hline Desember & 2.406 & 5.000 & 7.406 & 4.578 & 2.828 & 5.117 \\
\hline Total & 25.565 & 42.700 & 68.265 & 41.273 & 26.992 & 47.629 \\
\hline Rata-rata & 2.130 & 3.558 & 5.689 & 3.439 & 2.249 & 3.969 \\
\hline
\end{tabular}

c. Perhitungan Biaya Total Persediaan

Tabel 4.4 Kuantitas pesanan dan tingkat persediaan rata-rata perusahaan

Sumber : Hasil Olah Data Excel 2010,2017 
Tingkat persediaan rata-rata tahun 2016 sebesar 3.969 liter. Tingkat persediaan rata-rata tersebut merupakan hasil rata-rata

dari penjumlahan total persediaan awal dengan total persediaan akhir dibagi dua.

Untuk memenuhi kebutuhan persediaan bahan baku methanol agar proses produksi dapat berjalan lancar maka CV Mamabros Servicindo harus menanggung dua biaya persediaan yang meliputi biaya pemesanan dan biaya penyimpanan.

a. Biaya pemesanan

Biaya pemesanan selama suatu periode terdiri dari biaya administrasi dan biaya telepon. Berdasarkan pada tabel 4.5 dibawah ini jumlah biaya administrasi yaitu sebesar Rp 20.833/pesan, sedangkan biaya telepon sebesar Rp 25.200/pesan.

Sedangkan intisari biaya pemesanan disajikan pada tabel 4.5 di bawah ini:

Tabel 4.5. Komponen Biaya Pemesanan 2016

\begin{tabular}{l|l}
\hline Komponen Biaya & Jumlah \\
\hline Biaya administrasi & $\operatorname{Rp} 20.833$ \\
\hline Biaya telepon & $\operatorname{Rp} 25.200$ \\
\hline Total & $\mathbf{R p ~ 4 6 . 0 3 3}$ \\
\hline
\end{tabular}

2. Biaya penyimpanan

adalah biaya rata-rata yang dikeluarkan karena perusahaan melakukan penyimpanan dalam persediaan bahan baku di gudang dalam jangka waktu tertentu. Oleh karena itu biaya

Sumber : Hasil Olah Data Penulis,2017

penyimpanan yang terdapat selama penyimpanan bahan baku methanol seperti biaya pengawas gudang, biaya listrik, dan biaya perawatan/perbaikan gudang Besarnya biaya penyimpanan dapat dilihat di tabel berikut:

Tabel 4.6 Komponen Biaya Penyimpanan Bahan Baku 2016

\begin{tabular}{l|l}
\hline Komponen Biaya & Jumlah \\
\hline Biaya pengawas & $\mathrm{Rp} 2.419$ \\
\hline Biaya listrik & $\mathrm{Rp} 1.009$ \\
\hline Biaya perawatan/perbaikan gudang & $\mathrm{Rp} 176$ \\
\hline Total & $\mathrm{Rp} \mathrm{3.604}$ \\
\hline
\end{tabular}

Sumber : Hasil Olah Data Penulis,2017

Terlihat pada tabel diatas, jumlah besarnya biaya pengawas yang paling besar dari antara yang lain yaitu $\mathrm{Rp} 2.419$, dengan total biaya penyimpanan bahan baku methanol sebesar Rp 3.604 per liter.
3. Total biaya persediaan bahan baku

Tabel 4.7 Total biaya persediaan aktual perusahaan

\begin{tabular}{c|c|c|c}
\hline Tahun & $\begin{array}{c}\text { Biaya } \\
\text { Pemesanan }\end{array}$ & Biaya Penyimpanan & $\begin{array}{c}\text { Total Biaya } \\
\text { Persediaan }\end{array}$ \\
\hline 2016 & Rp 533.935 & Rp 6.412.117 & Rp 6.946.052 \\
\hline & & & \\
\hline
\end{tabular}

Sumber : Hasil Olah Data Penulis,2017 
Data di atas menjelaskan bahwa komponen biaya persediaan bahan baku yang menimbulkan biaya yang paling besar adalah biaya penyimpanan sebesar Rp 6.412.117 dengan total biaya persediaan sebesar Rp 6.946.052.

2. Pengendalian Persediaan Bahan Baku Menggunakan Metode EOQ

a. Pembelian bahan baku yang Ekonomis:

1. Biaya penyimpanan bahan baku per unit (H) Rp 3.604/Liter

2. Total kebutuhan bahan baku (D) 41.273 Liter

3. Biaya pesan sekali pesan (S) Rp 46.033

Maka besarnya pembelian bahan baku yang ekonomis dapat diperhitungkan dengan metode EOQ sebagai berikut :

$$
\begin{aligned}
& E O Q=\sqrt{\frac{2 S D}{H}} \\
& E O Q=\sqrt{\frac{2(46.033)(41.273)}{3.604}} \\
& E O Q=\sqrt{\frac{3.799 .840 .018}{3.604}} \\
& E O Q=\sqrt{1.054 .340} \\
& E O Q=1.027 \text { Liter }
\end{aligned}
$$

Berdasarkan data hasil perhitungan EOQ di atas, diketahui bahwa kuantitas pesanan bahan baku methanol yang optimal adalah sebesar 1.027 liter.

\section{b. Frekuensi Pemesanan Optimal}

Perhitungan frekuensi pemesanan bahan baku disajikan sebagai berikut

1. Total kebutuhan bahan baku (D) 41.273 Liter

2. Pembelian bahan baku ekonomis (EOQ) 1.027 Liter

$$
\begin{aligned}
& I=\frac{D}{E 0 Q} \\
& I=\frac{41.273}{1.077} \\
& I=40 \mathrm{kali}
\end{aligned}
$$

Frekuensi pesanan bahan baku kayu berdasarkan metode EOQ lebih banyak bila dibandingkan dengan frekuensi pesanan aktual yang telah dilakukan perusahaan. Frekuensi pesanan bahan baku methanol dengan metode perusahaan dilakukan sebanyak 12 kali, sedangkan pesanan dengan metode EOQ dilakukan sebanyak 40 kali.

$$
\text { c. Total Biaya Persediaan }
$$

Total biaya persediaan merupakan jumlah dari total biaya pemesanan dan total biaya penyimpanan per tahunnya. Biaya pemesanan diperoleh dari banyaknya kebutuhan bahan baku dikali biaya pemesanan setiap kali pesan lalu di bagi kuantitas pemesanan optimal bahan baku. Biaya penyimpanan diperoleh dengan mengalikan biaya penyimpanan per liter per tahun dengan kuantitas pemesanan optimal bahan baku lalu di bagi dua.

1. Total kebutuhan bahan baku (D)

$$
\text { 41.273 Liter }
$$

2. Pemesanan bahan baku yang ekonomis (Q) 1.027 Liter

3. Biaya pesan sekali pesan (S) Rp 46.033

4. Biaya penyimpanan bahan baku per liter $(\mathrm{H}) \mathrm{Rp} 3.604$

Penghitungan total biaya persediaan :

$$
\begin{aligned}
T I C & =\left(\frac{D}{Q} S\right)+\left(\frac{Q}{2} H\right) \\
T I C & =\left(\frac{41.273}{1.027} 46.033\right)+\left(\frac{1.027}{2} 3.604\right) \\
T I C & =(1.849 .954)+(1.850 .654) \\
T I C & =R p 3.700 .608
\end{aligned}
$$


Tabel 4.9 Total Biaya Persediaan Bahan Baku Berdasarkan Metode EOQ

\begin{tabular}{|c|c|c|c|}
\hline Tahun & $\begin{array}{c}\text { Biaya } \\
\text { Pemesanan }\end{array}$ & $\begin{array}{c}\text { Biaya } \\
\text { Penyimpanan }\end{array}$ & Total Biaya Persediaan \\
\hline 2016 & Rp 1.849 .954 & Rp 1.850 .654 & Rp 3.700.608 \\
\hline & & & \\
\hline
\end{tabular}

Sumber : Hasil Olah Data Penulis,2017

Data di atas menjelaskan bahwa komponen biaya persediaan bahan baku yang menimbulkan biaya yang paling besar adalah biaya penyimpanan sebesar $\mathrm{Rp}$ 1.850.654, dan total biaya persediaan menurut metode EOQ adalah $\mathrm{Rp}$ 3.700 .608 .
Dengan pemakaian Asumsi bahwa CV Mamabros Servicindo menerapkan persediaan yang memenuhi permintaan 95\% dan persediaan cadangan sebesar $5 \%$, sehingga dapat diperoleh $\mathrm{Z}$ dengan table normal sebesar 1,96 deviasi standar diatas dari rata - rata.

d. Menentukan persediaan pengaman

Tabel 4.10 Perhitungan Standar Deviasi

\begin{tabular}{c|c|c|c|c}
\hline Bulan & Kebutuhan Bahan Baku & $\dot{\mathrm{x}}$ & $(\mathrm{x}-\dot{\mathrm{x}})$ & $(\mathrm{x}-\dot{\mathrm{x}})_{2}$ \\
\hline Januari & 2.799 & 3.439 & $(640)$ & 409.658 \\
\hline Februari & 2.798 & 3.439 & $(641)$ & 410.868 \\
\hline Maret & 3.260 & 3.439 & $(179)$ & 32.011 \\
\hline April & 4.414 & 3.439 & 975 & 949.845 \\
\hline Mei & 3.100 & 3.439 & $(339)$ & 114.735 \\
\hline Juni & 345 & 3.439 & $(3.094)$ & 9.574 .136 \\
\hline Juli & 4.186 & 3.439 & 747 & 557.725 \\
\hline Agustus & 3.462 & 3.439 & 23 & 517 \\
\hline September & 4.232 & 3.439 & 793 & 629.520 \\
\hline Oktober & 4.672 & 3.439 & 1.233 & 1.520 .893 \\
\hline November & 3.426 & 3.439 & $(13)$ & 157 \\
\hline Desember & 4.578 & 3.439 & 1.139 & 1.297 .834 \\
\hline Total & 41.273 & & & 15.497 .898 \\
\hline
\end{tabular}

Sumber : Hasil Olah Data Excel 2010, 2007

Penghitungan standar deviasi sebagai berikut:

$$
\begin{aligned}
& S D=\sqrt{\frac{\sum(x-N)^{2}}{n}} \\
& S D=\sqrt{\frac{15.497 .899}{12}} \\
& S D=\sqrt{1.291 .491,5} \\
& S D=1.136
\end{aligned}
$$

Setelah di ketahui standar deviasi maka dapat dilakukan penghitungan persediaan pengaman (safety stock) sebagi berikut: Safety stock $=\mathrm{SD} \times \mathrm{Z}$ $=1.136 \times 1,88$

$=2.136$ liter
Jadi persediaan bahan baku yang harus disediakan sebagai persediaan pengaman adalah sebesar 2.136 liter.

e. Menentukan Reorder Point (Titik
Pemesanan Kembali)

Reorder Point dapat dihitung dengan menjumlahkan kebutuhan bahan baku selama Lead Time ditambah dengan jumlah persediaan pengamanan (Safety Stock). Waktu tunggu yang muncul akibat 
menunggu tibanya bahan baku di gudang

perusahaan adalah selama 7 hari.

Tabel 4.12 Reorder Point CV Mamabros Servicindo Tahun 2016

\begin{tabular}{c|c|c|c|c|c}
\hline Tahun & $\begin{array}{c}\text { Lead } \\
\text { Time }\end{array}$ & $\begin{array}{c}\text { Rata-Rata } \\
\text { Pemakaian/hari }\end{array}$ & $\mathrm{dL}$ & $\mathrm{SS}$ & $\mathrm{ROP}$ \\
\cline { 5 - 6 } & 7 Hari & 113 liter & 791 & 2.136 & 2.927 \\
\hline
\end{tabular}

Sumber : Hasil Olah Data Penulis,201

3. Analisis pengendalian persediaan bahan baku menggunakan metode JIT

Berikut ini perhitungan persediaan bahan baku dengan menggunakan metode Just In Time :

a. Menentukan jumlah pengiriman optimal bahan baku

1) $\mathrm{Q}=$ Total kebutuhan bahan baku sebesar 41.273 liter

2) $\mathrm{a}=$ Persediaan rata-rata bahan baku sebesar 3.969 liter

maka $n a=\frac{Q}{2 n}$

$$
n a=\frac{41.273}{2 \approx 3.969}
$$$$
n a=5
$$

Dari perhitungan diatas, maka diketahui jumlah pengiriman bahan baku yang optimal adalah 5 kali untuk setiap kali pemesanan bahan baku methanol.

b. Menentukan kuantitas pemesanan bahan baku yang optimal

1) $\mathrm{n}=$ jumlah pengiriman bahan baku optimal yaitu 5 kali

2) $\mathrm{Q}^{*}=$ kuantitas pesanan optimal EOQ

Maka, $Q_{n}=\sqrt{n} Q^{*}$

$$
\begin{aligned}
& Q n=\sqrt{5} \times 1.027 \\
& Q n=2.296
\end{aligned}
$$

Dengan demikian, kuantitas pemesanan yang optimal dengan metode Just In Time untuk memenuhi kebutuhan bahan baku methanol sebesar 2.296 liter.

c. Menentukan kuantitas pengiriman yang optimal untuk setiap kali pengiriman bahan baku

1) $\mathrm{Qn}=$ kuantitas pemesanan bahan baku optimal sebesar 2.296 liter

2) $n=$ jumlah pengiriman optimal 5 kali

maka, $q=\frac{\eta n}{n}$

$$
\begin{aligned}
& q=\frac{2.296}{5} \\
& q=459 \text { itter }
\end{aligned}
$$

Dari perhitungan di atas maka diketahui untuk memenuhi pemesanan sebesar 2.296 liter untuk setiap kali pesan, maka untuk setiap kali pengiriman bahan baku yang optimal sebesar 459 liter.

a. Menentukan frekunsi pemesanan bahan baku

1) $\mathrm{Q}=$ Total kebutuhan bahan baku sebesar 41.273 liter

2) $\mathrm{Qn}=$ kuantitas pemesanan bahan baku optimal sebesar 2.296 liter

Maka,

$$
N=\frac{Q}{Q_{n}}
$$


Dari perhitungan diatas, diketahui jumlah pemesanan bahan baku yang optimal adalah 18 kali untuk memenuhi kebutuhan bahan baku methanol 41.273 liter, ini lebih kecil dibandingkan dengan metode EOQ yang berjumlah 40 kali.

d. Menghitung biaya persediaan bahan baku

1) $\mathrm{T}=$ total biaya persediaan bahan baku Rp 6.946.052

2) $n=$ jumlah pengiriman optimal 5 kali

maka, biaya persediaan bahan baku adalah:

$$
T J I T=\frac{1}{\sqrt{n}}(T)
$$

$$
\begin{aligned}
& T J I T=\frac{1}{\sqrt{5}}(6.946 .052) \\
& T J I T=R p 3.056 .263
\end{aligned}
$$

Total biaya persediaan yang akan dikeluarkan oleh perusahaan jika menggunakan metode Just In Time sebesar Rp 3.056.263, biaya ini jauh lebih hemat apabila dibandingkan dengan biaya persediaan dengan metode Economic Order Quantity.

Maka pengendalian persediaan bahan baku methanol menggunakan metode Just In Time dirincikan pada tabel 4.13 berikut ini:

Tabel 4.13 Pengendalian persediaan menggunakan metode Just In Time

\begin{tabular}{c|c|c|c|c|c}
\hline Tahun & $\begin{array}{c}\text { Pemakaian/tah } \\
\text { un }\end{array}$ & $\begin{array}{c}\text { Biaya } \\
\text { Persediaan }\end{array}$ & $\begin{array}{c}\text { Frekunsi } \\
\text { Pengiriman/p } \\
\text { esa }\end{array}$ & $\begin{array}{c}\text { Frekuensi } \\
\text { Pemesanan }\end{array}$ & JIT \\
\hline 2016 & 41,273 liter & Rp 3.056.263 & 5 kali & 18 kali & $\begin{array}{c}2.296 \\
\text { liter }\end{array}$ \\
\hline
\end{tabular}

Sumber : Hasil Olah Data Penulis, 2017

4. Perbandingan Pengendalian

Persediaan Bahan Baku antara

Metode EOQ dengan JIT

Tabel 4.14 Perbandingan Pengendalian Persediaan antara Metode EOQ \& JIT

\begin{tabular}{c|c|c|c}
\hline Keterangan & $\begin{array}{c}\text { Kebijakan } \\
\text { Perusahaan }\end{array}$ & Metode EOQ & Metode JIT \\
\hline $\begin{array}{c}\text { Kebutuhan bahan } \\
\text { baku per tahun }\end{array}$ & $41.273 \mathrm{Liter}$ & $41.273 \mathrm{Liter}$ & 41.273 Liter \\
\hline $\begin{array}{c}\text { Kuantitas } \\
\text { pemesanan } \\
\text { optimal }\end{array}$ & $3.439 \mathrm{liter}$ & 1.027 liter & $2.296 \mathrm{liter}$ \\
\hline $\begin{array}{c}\text { Frekuensi } \\
\text { pemesanan/tahun }\end{array}$ & $12 \mathrm{kali}$ & $40 \mathrm{kali}$ & $18 \mathrm{kali}$ \\
\hline $\begin{array}{c}\text { Frekuensi } \\
\text { pengiriman/pesan }\end{array}$ & $1 \mathrm{kali}$ & $1 \mathrm{kali}$ & $5 \mathrm{kali}$ \\
\hline $\begin{array}{c}\text { Total Biaya } \\
\text { Persediaan }\end{array}$ & $\mathrm{Rp} 6.946 .052$ & $\mathrm{Rp} 3.700 .608$ & $\mathrm{Rp} \mathrm{3.056.263}$ \\
\hline
\end{tabular}

Sumber: Hasil Olah Data Penulis,2017

Dari tabel diatas terlihat perbandingan pengendalian persediaan bahan baku methanol antara kebijakan yang telah digunakan oleh CV Mamabros Servicindo

Batam dengan Metode Economic Order Quantity (EOQ) serta Metode Just In Time (JIT), dari tabel dapat diketahui bahwa kebutuhan bahan baku methanol sebesar 
41.273 liter. Kemudian kuantitas pembelian rata-rata bahan baku berdasarkan kebijakan perusahaan sebesar 3.439 liter sedangkan apabila menggunakan metode Economic Order Quantity (EOQ) maka kuantitas pemesanan yang optimal hanya sebesar 1.027 liter dan apabila menggunakan metode JIT kuantitas pemesanan yang optimal sebesar 2.296 liter. Untuk memenuhi kebutuhan bahan baku dengan kuantitas pemesanan yang optimal maka dengan metode Economic Order Quanitity (EOQ) dapat dilakukan 40 kali pemesanan bahan baku, jumlah ini lebih banyak jika dibandingkan dengan kebijakan perusahaan yang hanya 12 kali pemesanan, kemudian apabila menggunakan metode Just In Tme (JIT) pemesanan bahan baku dapat dilakukan sebanyak 18 kali dengan pengiriman 5 kali untuk setiap kali melakukan pemesanan bahan baku. Kemudian total biaya persediaan yang dikeluarkan berdasarkan kebijakan perusahaan sebesar Rp 6.946.052. Apabila menggunakan metode Economic Order Quantity (EOQ maka total biaya persediaan bahan baku methanol sebesar Rp 3.700.608. Sehingga apabila dibandingkan dengan kebujakan perusahaan maka biaya persediaan dengan metode Economic Order Quantity (EOQ) dapat menghemat biaya persediaan sebesar Rp 3.245.444. Sedangkan apabila menggunakan metode Just In Time (JIT) total biaya persediaan bahan baku methanol sebesar $\mathrm{Rp}$ 3.056.263, apabila dibandingkan dengan kebijkan perusahaan maka dapat dilakukan penghematan biaya persediaan sebesar Rp 3.889.789, kemudian jika dibandingkan dengan metode Economic Order Quantity maka selisih biaya persediaan sebesar Rp 644.345 .

\section{SIMPULAN DAN SARAN}

\section{Kesimpulan}

Berdasarkan hasil penelitian dan pembahasan yang telah dilakukan untuk mengetahui analisis perbandingan persediaan bahan baku antara metode EOQ dengan JIT, berdasarkan rumusan masalah dan hasil penelitian di atas maka kesimpulan yang dapat diambil adalah sebagai berikut :

1. Dari analisis EOQ, dapat disimpulkan kuantitas pemesanan optimal sebesar 1.027 liter, dengan frekuensi pemesanan 40 kali. Lalu, persediaan pengaman yang diperoleh sebesar 2.226 liter dan titik pemesanan kembali bahan baku methanol yaitu 3.017 liter dan total biaya persediaaannya sebesar Rp 3.700.608.

2. Dari analisis JIT, disimpulkan kuantitas pemesanan optimal sebesar 2.296 liter, dengan frekuensi pemesanan 18 kali dan frekuensi pengiriman sebanyak 5 kali sebesar 459 liter. Sedangkan total biaya persediaan metode JIT sebesar Rp 3.056.263

3. Berdasarkan analisis kedua metode diatas dapat disimpulkan bahwa kedua sistem tersebut, baik JIT dan EOQ lebih efisien dalam penghitungan total biaya persediaan dibandingkan dengan sistem persediaan yang telah dilakukan oleh CV Mamabros Servicindo Batam. EOQ dapat menghemat sekurang-kurangnya $46 \%$ dari total biaya perusahaan. Sementara hasil yang didapat dalam analisis sistem JIT dapat menghemat biaya kurang lebih sebesar 55\% dari total biaya perusahaan. Dengan demikian, hasil dari analisis tersebut menunjukkan bahwa kedua sistem, baik EOQ dan JIT dapat bekerja secara tepat dan efisien pada CV Mamabros Servicindo Batam. Namun sistem JIT lah yang mempunyai efisiensi yang lebih besar bila dilihat 
dari besarnya biaya persediaan dan besarnya penghematan biaya dibandingkan dengan biaya persediaan perusahaan.

\section{Saran}

Berdasarkan kesimpulan yang diperoleh dalam penelitian ini, maka diajukan saran-saran sebagai berikut :

1. Penelitian ini diharapkan dapat memberikan masukan kepada pihak perusahaan yaitu $\mathrm{CV}$ Mamabros Servicindo Batam untuk memperhatikan pengendalian persediaan bahan baku agar dapat lebih meningkatkan produktivitas produksi serta mengefisienkan biaya persediaaan.

2. CV Mamabros Servicindo Batam disarankan untuk menggunakan supplier yang berlokasi tidak jauh dari perusahaan, untuk memudahkan perusahaan dalam pengadaan bahan baku. Sehingga tidak perlu memesan bahan baku dalam jumlah yang besar yang dapat menyebabkan penimbunan di gudang. Letak lokasi supplier yang berdekatan juga diharuskan jika perusahaan menggunakan metode pengendalian persediaan Just In Time.

\section{UCAPAN TERIMAKASIH}

Dalam penyusunan dan penyelesaian skripsi ini penulis menyadari bahwa kemampuan yang penulis miliki sangat terbatas, sehingga penulis mendapatkan hambatan maupun kesulitan. Akan tetapi dengan ketekunan dan kesabaran serta dukungan yang luar biasa dari berbagai pihak maka penyusunan skripsi ini dapat diselesaikan dengan baik. Oleh karena itu, penulis menyampaikan rasa hormat dan ucapan terima kasih yang sebesar-besarnya kepada :

\section{Pihak Politeknik Negeri Batam}

Penulis ucapkan terima kasih banyak kepada seluruh pihak dosen, staf pendidik di Politeknik Negeri Batam. Sudah membantu dalam menyelesaikan pendidikan Diploma IV (D4), memberikan ilmu pengetahuan yang banyak dan sangat bermanfaat untuk penulis. Ucapan terima kasih yang tidak terhingga kepada dosen-dosen yang telah membantu dalam menyelesaikan penelitian ini baik dosen pembimbing sekaligus dosen wali penulis yaitu Ibu Dwi Kartikasari, dosen penguji dan dosen lainnya yang sudah memberikan masukan dan saran dalam melakukan penelitian ini.

1. Pihak CV Mamabros Serivicindo Batam Penulis juga mengucapkan terima kasih kepada pihak manajemen $\mathrm{CV}$ Mamabros Serivicindo Batam yang sudah memberikan ijin bagi penulis untuk meneliti. Selain itu juga terima kasih antar bantuan dan dukungan yang diberikan kepada penulis selama menyelesaikan tugas penelitian ini.

2. Keluarga

Ucapan terima kasih yang tak terhingga kepada keluarga yang sudah sangat mendukung dan memberikan semangat dalam menyelesaikan studi dan penelitian ini. Terima kasih kepada kedua orang tua yang selalu mendoakan yang terbaik dan memberikan inspirasi bagi penulis.

3. Teman

Penulis juga mengucapkan terima kasih kepada teman-teman sejawat yang telah memberikan masukan dan dukungan selama menjalankan studi dan penelitian ini, sehingga dapat menyelesaikannya dengan baik. Semoga seluruh mahasiswa/i Administrasi Bisnis terus sukses dalam karir dan menggapai citacita yang diinginkan.

\section{DAFTAR PUSTAKA}

Assauri, S. (2008). Manajemen Produksi. Jakarta: Lembaga Penerbit Fakultas Ekonomi Universitas Indonesia.

Fahma, A. A., ZA.Z., \& Goretti.M.W.NP. (2016). Analisis Metode Economic 
Order Quantity Sebagai Dasar Pengendalian Persediaan Bahan Baku Pembantu. Jurnal Administrasi Bisnis (JAB). VOL 33 No 1

Fajrin, E. H. (2015). Analisis Pengendalian Bahan Baku Menggunakan Metode Economic Order Quantity (EOQ) Pada Perusahaan Roti Bonansa. Skripsi Universitas Negeri Semarang.

Ferdinand, A. (2006). Metode Penelitian Manajemen: Pedoman Penelitian untuk Penulisan Skripsi, Tesis, dan Disertasi Ilmu Manajemen. Badan Penerbit Universitas Diponergoro.

Garrison, H.R \& Noreen,E. W. (2006). Akuntansi Manajerial. Jakarta: Salemba Empat.

Gaspersz, V. (2012). All In One Integrated Total Quality Talent Management. Jakarta: Gramedia.

Guga, E., \& Musa,O. (2015). Inventory Management Through EOQ Model a case study of SHPRESA LTD.ALABNIA. International Journal of Economics, commerce and Management Vol III .

Hayundra, M, M., \& Kamal, M. (2015). Perbandingan Sistem economic order dan Just in Time Pada Pengendalian Persediaan Bahan Baku. Diponegoro Journal of Management Vol 4 No.2, 1-14.

Heizer, B. R. (2008). Manajemen Operasi. Jakarta: Salemba Empat.

Herjanto, E. (2007). Manajemen Operasi. Jakarta: Grasindo.

Kuncoro, M. (2007). Metode Kuantitatif: Teori dan Aplikasi untuk Bisnis dan
Ekonomi . Yogyakarta: UPP AMP YKPN.

Lestari, C. D. (2012). Analisis Penerapan Economic Order Quantity (EOQ) dalam Manajemen Persediaan dan Pengaruhnya Terhadap Efektivitas, Efisiensi, dan Likuiditas Perusahaan. Universitas Indonesia.

Maulana, A. (2015). Analisis Efisiensi Persediaan Bahan Baku Susu Sapi Murni dengan Metode Economic Order Quantity pada Soto Sedeep . Diponegoro Journal of Management Vol 4 No 2, 1-14.

Nafarin, M. (2004). Penganggaran Perusahaan. Jakarta: Salemba Empat.

Nurnajamuddin, M. H. (2007). Manajemen Produksi Modern. Jakarta: PT Bumi Aksara.

Nuryanto, A. (2010). Analisis Perbandingan Pengendalian Persediaan Bahan Baku Kain Micropplar Fleece Antara Pendekatan Model EOQ Dengan Just In Time Inventory Control (JIT/EOQ) Pada CV Cahyo Nugroho Jati Sukoharjo. Skripsi Universitas Sebelas Maret Surakarta.

Rangkuti, F. (2007). Manajemen Persediaan. Jakarta : Raja Grafindo Persada.

Rifqi, L. H. (2012). Efisiensi Biaya Pengendalian Bahan Baku Menggunakan Metode Economic Oder Quantity (EOQ) pada PT Sari Warna Asli V Kudus. Universitas Negeri Semarang.

Riyanto, B. (2011). Dasar-dasar Pembelanjaan Perusahaan. Yogyakarta: Penerbit GPEE. 
Saputra, N. (2015). Analisis Implementasi Just In Time Terhadap Peningkatan Produktivitas Perusahaan Pada PT Ras Jaya. Jurnal Manajemen Univeristas Islam Bandung.

Simamora, H. (2002). Manajemen Sumber Daya Manusia. Yogyakarta: BPFE.

Slamet, A. (2007). Penganggaran Perencanaan dan Pengendalian Usaha. Semarang: UNNES PRESS.

Sudjana, N. (2005). Metode Statistika Edisi ke 6. Bandung: Tarsito.

Sugiyono, Prof Dr. (2011). Metode Penelitian Administrasi. Bandung: CV Alfabeta.

Suharsimi, A. (2010). Prosedur Penelitian Suatu Pendekatan Praktik. Jakarta: Rineka Cipta.

Sulistiyowati, U. (2006). Analisis Perencanaan dan Pengendalian Persediaan Bahan Baku dengan Pendekatan Model JIT/EOQ Pada Percetakan Bintang Pelajar . Skripsi Universitas Sebelas Maret Surakarta.

Suliyanto. (2006). Metode Riset Bisnis. Yogyakarta: Andi.

Sumayang, L. (2003). Dasar-dasar manajemen Produksi dan Operasi. Jakarta: Salemba Empat.

Taufik,M. M. (2013). Analisis Persediaan Bahan Baku Kertas Menggunakan Metode EOQ (Economic Order Quantity) Pada Harian Tribun Makassar. Skripsi Universitas Hasanuddin.

Silahkan mengacu ke petunjuk 